\title{
BMJ Open Uptake of provider-initiated HIV and syphilis testing among heterosexual STD clinic patients in Guangdong, China: results from a cross- sectional study
}

\author{
Peizhen Zhao (D) , ${ }^{1,2,3}$ Weiming Tang (D) , ${ }^{1,2,3,4}$ Huanhuan Cheng, ${ }^{5}$ Shujie Huang, ${ }^{1,2,3}$ \\ Heping Zheng, ${ }^{1,2,3}$ Bin Yang, ${ }^{1,2,3}$ Cheng Wang (1D) ${ }^{1,2,3}$
}

To cite: Zhao P, Tang W, Cheng $\mathrm{H}$, et al. Uptake of provider-initiated HIV and syphilis testing among heterosexual STD clinic patients in Guangdong, China: results from a crosssectional study. BMJ Open 2020;10:e041503. doi:10.1136/ bmjopen-2020-041503

- Prepublication history for this paper is available online. To view these files, please visit the journal online (http://dx.doi. org/10.1136/bmjopen-2020 041503).

$\mathrm{PZ}$ and $\mathrm{CW}$ contributed equally.

Received 11 June 2020

Revised 03 December 2020

Accepted 12 December 2020

Check for updates

(C) Author(s) (or their employer(s)) 2020. Re-use permitted under CC BY-NC. No commercial re-use. See rights and permissions. Published by BMJ.

For numbered affiliations see end of article.

Correspondence to

Dr Cheng Wang;

wangcheng090705@gmail.com

\section{ABSTRACT}

Objectives Underscreening of HIV and syphilis in clinical settings is pervasive in resource-constrained settings. Heavy patient loads and competing health priorities in these settings inhibit provider's ability to meet screening coverage targets. The objective of this study was to examine determinants of provider-initiated HIV and syphilis testing uptake at sexually transmitted disease (STD) clinics in China.

Design A cross-sectional study was performed between July 2016 and December 2016.

Setting Seven STD clinics in Guangdong Province, China. Participants Heterosexual STD clinic patients met the inclusion criteria, regardless of their interest in receiving HIV or syphilis testing.

Outcome measures The syphilis and HIV testing uptake determined by patient receipt of results.

Results A total of 1943 individuals were recruited in this study. Among those participants, $60.6 \%$ (1177/1943) and $74.3 \%$ (1443/1943) conducted HIV testing and syphilis testing during the study, respectively, of whom, $2.2 \%$ (26/1177) and $21.5 \%(310 / 1443)$ were found to be HIVpositive and syphilis-positive, respectively. The most common reason for rejecting HIV and syphilis testing was a low self-perceived risk of HIV and syphilis infection. After adjusting for covariates, condom use in the last sexual act consistent condom use in the last 6 months, having paid sex in the last 6 months and having received any kind of HIV/STD-related knowledge during the last 12 years were positively associated with both HIV and syphilis testing uptake.

Conclusions The low-level of HIV and syphilis testing uptake, alongside with the high-level of engagement in risky sexual behaviours among heterosexual STD clinic patients, warranted a more targeted and intensive behavioural interventions to promote HIV and syphilis testing in this population.

\section{INTRODUCTION}

Sexually transmitted HIV infections have become a public health concern globally. An estimated $85 \%$ of HIV infections are

\section{Strengths and limitations of this study}

This is one of the very limited studies analysing determinants of provider-initiated HIV/syphilis test uptake among 1943 heterosexual sexually transmitted diseaseclinic patients in China.

- The number of syphilis and HIV testing uptake was determined by patient receipt of results, making the outcome more reliable.

- All the data were collected through self-report, which may be prone to information bias.

- The cross-sectional nature of the study design makes it difficult to determine causal interference.

transmitted through heterosexual intercourse worldwide. ${ }^{1}$ In China, heterosexual transmission has been reported to account for $69.9 \%$ of HIV infections. ${ }^{2}$ Integration of HIV services into the clinical care of routine sexually transmitted diseases (STD) has been proven useful for expanding HIV testing and treatment among populations at risk of both infections in many low-income and middleincome countries. ${ }^{3-5}$

In 2014, considering the heavy burden of HIV-syphilis coinfection and syphilis epidemic, the Chinese centres for disease control and prevention issued providerinitiated $\mathrm{HIV} /$ syphilis testing and counselling (PITC) guideline to increase provider-initiated $\mathrm{HIV} /$ syphilis testing in China. ${ }^{6}$ However, promoting active HIV and syphilis testing provided by physicians to all patients presenting for STD medical care is no small task due to the high workload of clinicians in China. ${ }^{7}$ To address this challenge, several studies suggested strategies of payfor-performance, strengthened training and propaganda among physicians to encourage provider HIV/syphilis testing. ${ }^{6} 8$ Although a 
marked increase in HIV/syphilis testing rate among STD clinic patients was observed with the application of these strategies, the rates of HIV testing ${ }^{6}(56.7 \%)$ and syphilis testing ${ }^{6}(68.6 \%)$ were still much lower than the target that $90 \%$ of people with HIV and $90 \%$ of people with syphilis should be aware of their infection status by the year $2020 .{ }^{9}{ }^{10}$ To date, limited studies have been conducted to analyse the factors associated with the uptake of HIV/ syphilis testing from STD clinic patients' perspective in the context of PITC programme. ${ }^{1-13}$

In light of the high proportions $(99.1 \%)$ of heterosexual population among STD clinic patients, ${ }^{13}$ this study focused on heterosexual STD clinic patients to analyse determinants of provider-initiated HIV/syphilis test uptake from patients' perspective in China.

\section{METHODS}

\section{Project setting}

We conducted a cross-sectional study in Guangdong Province in Southern China between July 2016 and December 2016. Guangdong Province was chosen for this study because of a high burden of sexually transmitted HIV infection and syphilis. ${ }^{14}$ In 2018, the average burden of syphilis in China was 35.6 cases per 100000 population with Guangdong Province reporting 50.3 cases per 100 000 population. ${ }^{15}$ Guangdong has consistently ranked first by the number of newly reported syphilis cases in China during the last decade. ${ }^{16}$ The Pearl River Delta is the population-dense, urbanised central region of Guangdong Province that includes 7 of the province's 21 municipalities. The Pearl River Delta region of Guangdong has a disproportionate burden of sexually transmitted HIV infection and syphilis. ${ }^{17}$

\section{Study participants}

Two cities (Dongguan city and Zhongshan city) in the Pearl River Delta were selected to implement this research based on laboratory capacity, availability of trained research assistants and space to conduct the interview. Three public STD clinics in Dongguan city and four public STD clinics in Zhongshan city were chosen using a probability proportional-to-size sampling method. The number of public STD patients per day at each site was estimated with administrative data.

\section{Sample size}

The primary outcome of this study was test uptake defined by the receipt of test results. A previous study reported $70 \%$ of syphilis testing uptake among STD clinics attendees in China. ${ }^{8}$ We applied two-sided CIs for one proportion method to estimate a sample size of 1513 for this study to produce a two-sided $95 \%$ CI with a width equal to 0.050 . According to the number of public STD patients per day at each site, the total number of study participants at each site ranged from 200 to 300 over the course of 6 months study.

\section{Study procedure}

The survey items were created based on discussions with HIV/STD experts, STD physicians and policymakers. We also piloted the survey with 20 volunteer STD patients. The purpose of this formative research was to test survey items and examine local syphilis/HIV testing capacity, referral patterns and the availability of treatment and care services. These pilot data were not included in the final analysis.

From July 2016 to December 2016, potential study subjects were identified by physicians and research assistants at selected STD clinics. Patients were eligible for participation if they met the following inclusion criteria, regardless of their interest in receiving HIV or syphilis testing: self-identified heterosexual, engaged in vaginal or anal sex with an opposite-sex partner in the past 12 months, at least 18 years of age, and willing to provide written informed consent. For all eligible patients, physicians actively recommended them to conduct HIV and syphilis testing and invited them to fill out a questionnaire no matter whether or not they accepted the testing. Participation in this survey was voluntary and no incentives were given to patients to participate in the study. All surveys were self-administered and checked by a research assistant for completeness.

For participants who accepted HIV or syphilis testing, the results of the syphilis and HIV test were available to all participants within 2 hours, and the results were collected by research assistants at the end of the survey. Venous samples were tested for HIV by enzyme-linked immunoassay (Lizhu Biotech, Zhuhai, China) and syphilis by the rapid plasma regains test (Lizhu Biotech, Zhuhai, China) and Treponema pallidum particle agglutination test (Rongsheng Biotech, Shanghai, China). Both the syphilis and HIV test kits were approved by the China's State Food and Drug Administration. Confidentiality of testing results was ensured when the participants were informed of their results. Post-test counselling and appropriate medical care for STD/HIV was implemented according to standard STD clinic procedures.

\section{Measures}

Sociodemographic and behavioural variables

Sociodemographic information included age, gender, marital status, education and monthly income. Behavioural variables included condom use in the last sexual act, frequency of condom use in the last 6 months and ever engaged in paid sex in the last 6 months.

\section{HIV and syphilis testing and related medical service variables}

HIV and syphilis testing and related medical services included acceptance of HIV and syphilis testing uptake during this visiting, reasons for not conducting HIV and syphilis testing, STD infection history, received education on HIV and STD-related knowledge, whether the participants returned for results and the results of the testing. 


\section{Statistical analysis}

All data were double-entered with logic checks using EpiData V.3.0. Descriptive analysis was performed to describe sociodemographics, sexual behaviours and $\mathrm{HIV} /$ syphilis testing. A series of univariate and multivariable logistic regressions were conducted to explore factors associated with HIV testing uptake, syphilis testing uptake, HIV infection and syphilis infection, respectively. In the multivariable model, we adjusted for age (continuous), gender, marital status, educational attainment and monthly income. All data were analysed using SAS V.9.4 (SAS Cary, North Carolina, USA).

\section{Patient and public involvement}

The participants and general public were not involved in the development of the research question, outcome measures, design, recruitment and conduct of this study.

\section{RESULTS}

A total of 1943 participants were recruited in this study and filled out the questionnaire. Of those participants, a total of $428(22.0 \%)$ participants refused both tests, 1177 $(60.6 \%)$ conducted HIV test, $1443(74.3 \%)$ conducted syphilis test, 1105 (56.9\%) conducted both tests. Among those who tested for either HIV or syphilis, 2.2\% $(26 / 1177)$ and $21.5 \%(310 / 1443)$ had a reactive result for HIV test and syphilis test, respectively (table 1).

The majority of participants was between 25 and 35 years old $(40.1 \%)$, was men $(50.6 \%)$, was married $(79.6 \%)$, had a junior high school degree $(40.1 \%)$ and had an annual income between US $\$ 5001$ and US $\$ 9000$ $(39.8 \%)$. Around one-tenth (12.9\%) had paid sex during the last 6 months, of whom $50.4 \%$ did not use condoms in the last paid sexual act. Most participants (83.1\%) used condoms inconsistently when engaged in sexual intercourse in the last 6 months (table 1).

Among those who refused either HIV testing or syphilis testing, the most common reason was that they think it is not necessary to do the testing $(71.5 \%$ for HIV testing and $67.6 \%$ for syphilis testing), followed by having ever received a testing before (14.6\% for HIV testing and $17.2 \%$ for syphilis testing) and worrying about confidentiality (6.1\% for HIV testing and $8.2 \%$ for syphilis testing). In addition, among those who refused HIV testing, most participants $(98.0 \%)$ reported not ever having HIV testing in the last 12 months, and $46.3 \%(19 / 41)$ of this population reported not using condoms in the last paid sex. The same situation was also found in the participants who refused syphilis testing (table 2).

\section{Factors associated with HIV and syphilis testing uptake}

In terms of HIV testing uptake, after adjusted for age, gender, ethnic, education level, marital status and monthly income, multivariable logistic regression analysis indicated that condom use in the last sexual encounter (adjusted OR (aOR): 3.25, 95\% CI 2.61 to 4.05 ), having paid sex in the last 6 months (aOR: 3.19, 95\% CI 2.24 to
4.56 ), consistently condom use in the last 6 months (aOR: $1.96,95 \%$ CI 1.44 to 2.67 ), received any kind of HIV/ STD-related knowledge in the last 12 months (aOR: 1.94, 95\% CI 1.58 to 2.40 ) were positively associated with HIV testing uptake (table 3 ).

For syphilis testing uptake, the participants who ever had a diagnosis of STD (aOR=1.78, 95\% CI 1.29 to 2.44), condom use in the last sexual encounter $(\mathrm{aOR}=2.23$, $95 \%$ CI 1.76 to 2.84), consistent condom use in the last 6 months (aOR: 2.37, 95\% CI 1.79 to 3.15), had paid sex in the last 6 months (aOR=1.84, 95\% CI 1.27 to 2.67) and received any kind of HIV/STD-related knowledge in the last 12 months ( $\mathrm{aOR}=2.91,95 \%$ CI 2.25 to 3.77 ) were more likely to be tested for syphilis (table 3 ).

\section{Factors associated with HIV and syphilis infection}

For HIV infection, after adjusted for age, gender, ethnicity, education level, marital status and monthly income, multivariable logistic regression analysis indicated that participants who engaged in paid sex in the last 6 months $(\mathrm{aOR}=2.00,95 \%$ CI 1.24 to 3.12$)$ were more likely to be infected with HIV (table 4).

For syphilis infection, the participants who ever had a diagnosis of STD (aOR=5.31, 95\% CI 3.93 to 7.18) and not used condom in the last sexual encounter $(\mathrm{aOR}=1.75$, 95\% CI 1.29 to 2.39 ) were positively correlated with syphilis infection (table 4 ).

\section{DISCUSSION}

HIV and syphilis testing uptake remain low among STD clinic patients in China, although provider-initiated HIV and PITC guideline have been initiated since $2007{ }^{18}$ This study extended the existing literature by focusing on heterosexual STD clinic patients and analysing determinants to providerinitiated HIV and syphilis testing uptake. Data suggested that many barriers still exist preventing patients from accepting HIV and syphilis testing in China. Findings from this study inform improvement of HIV and syphilis testing promotion strategies among STD clinic patients in the context of PITC programme.

We found a low HIV and syphilis testing uptake among heterosexual STD clinic patients in China. This rate is much lower than previously reported in Zambia, ${ }^{19}$ Botswana $^{20}$ and South Africa, ${ }^{21}$ whereas other studies showed that social stigma against HIV and STD, ${ }^{22}$ fear of testing ${ }^{23}$ and lack of testing information ${ }^{24}$ are main contributors of limiting HIV and syphilis testing, our study found that the most common barrier in this sample of Chinese heterosexual STD clinic patients was a perceived low risk of HIV and syphilis infection. This highlights the importance of improving knowledge and awareness related to HIV and syphilis infection among heterosexual STD clinic patients. Internet-based interventions, such as through mobile communication apps, have been well developed and widely implemented on increasing health sexual knowledge and behaviours globally. ${ }^{25}$ Given the high internet accessibility in China, future strategies explored 


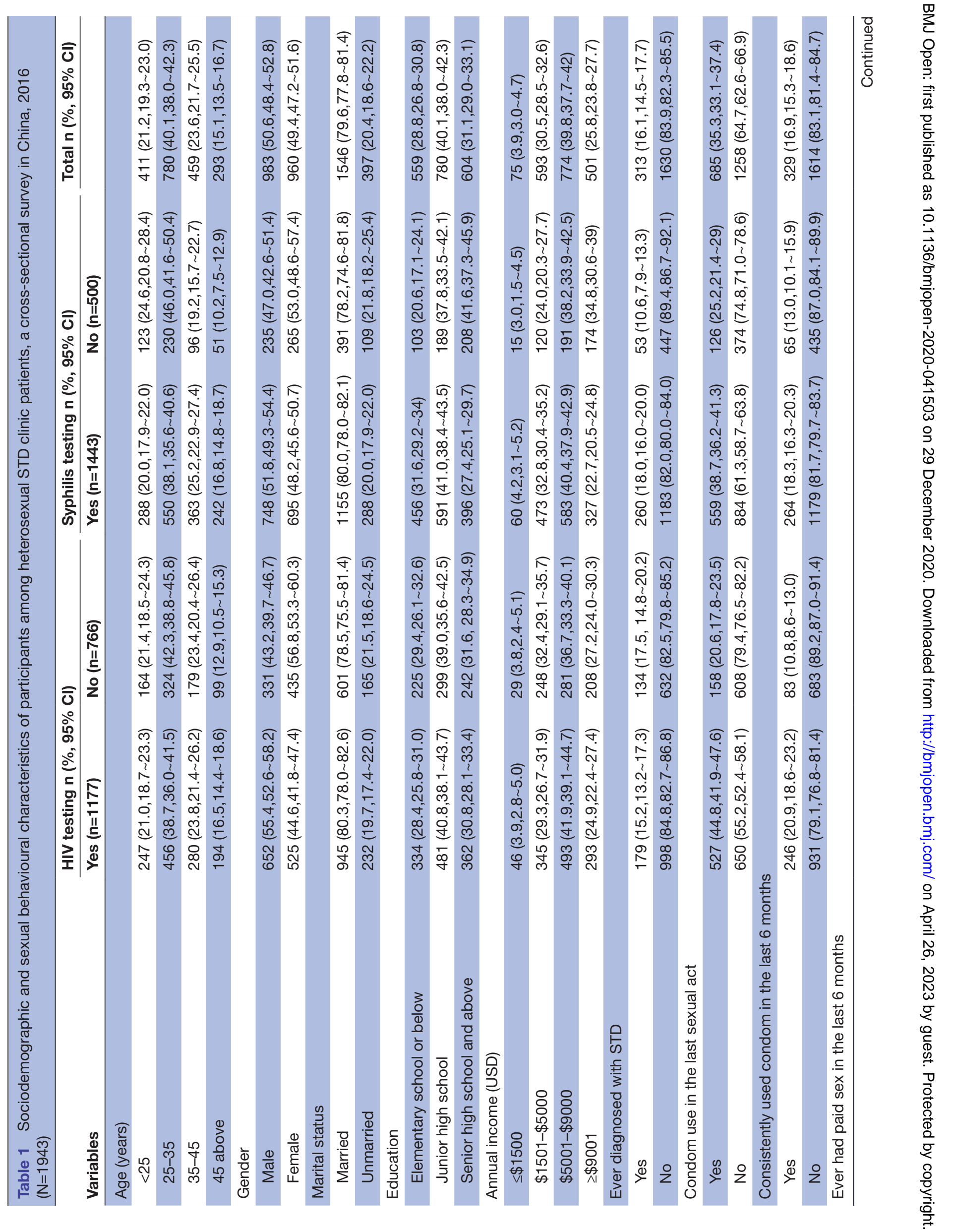




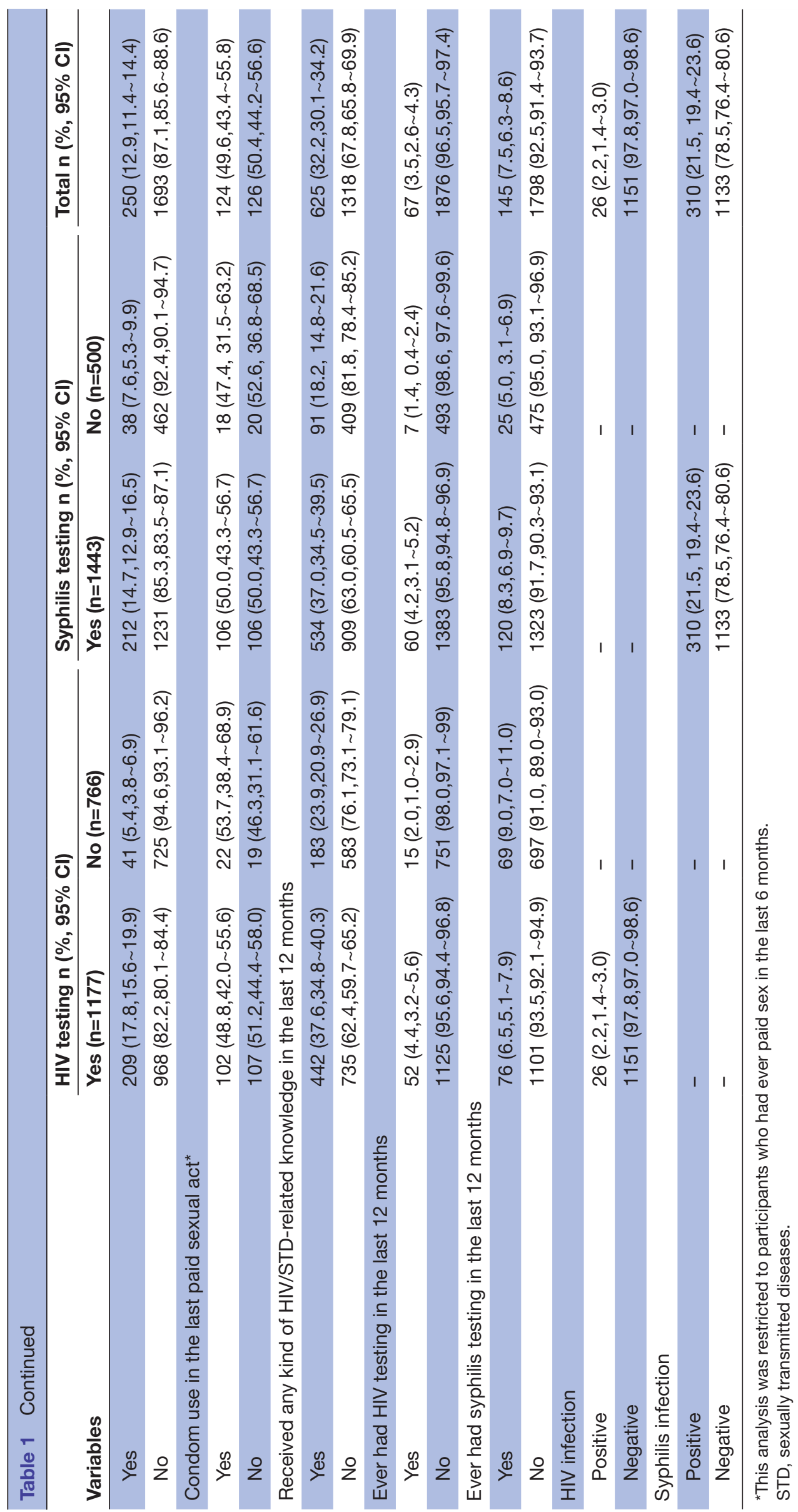


Table 2 Reasons for not conducting HIV or syphilis testing

\begin{tabular}{|c|c|c|}
\hline Reasons & $\begin{array}{l}\text { HIV testing } \\
(n=766, \%)\end{array}$ & $\begin{array}{l}\text { Syphilis testing } \\
(n=500, \%)\end{array}$ \\
\hline High cost for test & $8(1.0,0.3 \sim 1.8)$ & $6(1.2,0.2 \sim 2.2)$ \\
\hline $\begin{array}{l}\text { Worried about } \\
\text { confidentiality }\end{array}$ & $47(6.1,4.4 \sim 7.8)$ & $41(8.2,5.8 \sim 10.6)$ \\
\hline $\begin{array}{l}\text { Not necessary for } \\
\text { test }\end{array}$ & $\begin{array}{l}548 \text { (71.5, } \\
68.3 \sim 74.7)\end{array}$ & $\begin{array}{l}338(67.6 \\
63.5 \sim 71.7)\end{array}$ \\
\hline $\begin{array}{l}\text { Worried about } \\
\text { discrimination }\end{array}$ & $11(1.4,0.6 \sim 2.3)$ & $2(0.4,0.0 \sim 1.0)$ \\
\hline $\begin{array}{l}\text { Ever received a } \\
\text { test }\end{array}$ & $\begin{array}{l}112(14.6 \\
12.1 \sim 17.1)\end{array}$ & $86(17.2,13.9 \sim 20.5)$ \\
\hline $\begin{array}{l}\text { Worried about } \\
\text { positive results }\end{array}$ & $15(2.0,1.0 \sim 2.9)$ & $14(2.8,1.4 \sim 4.2)$ \\
\hline Others & $25(3.3,2.0 \sim 4.5)$ & $13(2.6,1.2 \sim 4.0)$ \\
\hline
\end{tabular}

on improving acceptability of HIV and syphilis testing uptake through internet are warranted.

Our study showed a high proportion of both HIV and syphilis infection among individuals who conducted HIV and syphilis testing. This proportion is higher than previously reported in other studies in China, ${ }^{13}$ South Africa, ${ }^{26}$ Vietnam. ${ }^{27}$ Additionally, among those testers, we found that around one-tenth of participants had ever engaged in paid sex in the last 6 months, but only half of those used condoms in the last paid sex, which is similar to another study in China. ${ }^{13}$ These indicate that heterosexual STD clinic patients bear a high burden of HIV and syphilis infection, warranting the necessity of improving HIV and syphilis test uptake among this population.

Our data found that condom use was positively associated with both HIV and syphilis testing. This finding was consistent

Table 3 Factors associated with HIV and syphilis testing among heterosexual STD clinic patients, a cross-sectional survey in China, $2016(n=1943)$

\begin{tabular}{|c|c|c|c|c|c|c|c|c|}
\hline \multirow[b]{3}{*}{ Variables } & \multicolumn{4}{|l|}{ HIV testing* } & \multicolumn{4}{|l|}{ Syphilis testing* } \\
\hline & \multirow{2}{*}{$\begin{array}{l}\text { Crude model } \\
\text { OR }(95 \% \mathrm{Cl})\end{array}$} & \multirow[b]{2}{*}{$\mathbf{P}$} & \multirow{2}{*}{$\begin{array}{l}\text { Adjusted model } \\
\text { OR }(95 \% \mathrm{Cl})\end{array}$} & \multirow[b]{2}{*}{$\mathbf{P}$} & \multirow{2}{*}{$\begin{array}{l}\text { Crude model } \\
\text { OR }(95 \% \mathrm{Cl}) \\
\end{array}$} & \multirow[b]{2}{*}{$\mathbf{P}$} & \multirow{2}{*}{$\begin{array}{l}\text { Adjusted model } \\
\text { OR }(95 \% \mathrm{Cl})\end{array}$} & \multirow[b]{2}{*}{$\mathbf{P}$} \\
\hline & & & & & & & & \\
\hline \multicolumn{9}{|c|}{ Ever diagnosed with STD } \\
\hline Yes & $1.17(0.92 \sim 1.49)$ & 0.198 & $1.19(0.93 \sim 1.53)$ & 0.173 & $1.88(1.37 \sim 2.56) \dagger$ & $<0.001$ & $1.78(1.29 \sim 2.44) \dagger$ & $<0.001$ \\
\hline No & Ref. & & Ref. & & Ref. & & Ref. & \\
\hline \multicolumn{9}{|c|}{ Condom use in the last sexual encounter } \\
\hline Yes & $3.06(2.48 \sim 3.77) \dagger$ & $<0.001$ & $3.25(2.61 \sim 4.05) \dagger$ & $<0.001$ & $3.06(2.48 \sim 3.77) \dagger$ & $<0.001$ & $2.23(1.76 \sim 2.84) \dagger$ & $<0.001$ \\
\hline No & Ref. & & Ref. & & Ref. & & Ref. & \\
\hline \multicolumn{9}{|c|}{ Consistently used condom in the last 6 months } \\
\hline Yes & $1.51(1.12 \sim 2.02) \dagger$ & $<0.001$ & $1.96(1.44-2.67) \dagger$ & $<0.001$ & $2.22(1.69 \sim 2.90) \dagger$ & $<0.001$ & $2.37(1.79 \sim 3.15) \dagger$ & $<0.001$ \\
\hline No & Ref. & & Ref. & & Ref. & & Ref. & \\
\hline \multicolumn{9}{|c|}{ Ever had paid sex in the last 6 months } \\
\hline Yes & $3.80(2.70 \sim 5.36) \dagger$ & $<0.001$ & $3.19(2.24 \sim 4.56) \dagger$ & $<0.001$ & $2.08(1.46 \sim 2.97) \dagger$ & $<0.001$ & $1.84(1.27 \sim 2.67) \dagger$ & 0.001 \\
\hline No & Ref. & & Ref. & & Ref. & & Ref. & \\
\hline \multicolumn{9}{|c|}{ Condom use in the last paid sexual act } \\
\hline Yes & $0.82(0.42 \sim 1.61)$ & 0.571 & $0.93(0.41 \sim 2.12)$ & 0.867 & $0.78(0.42 \sim 1.46)$ & 0.436 & $1.21(0.58 \sim 2.52)$ & 0.621 \\
\hline No & Ref. & & Ref. & & Ref. & & Ref. & \\
\hline \multicolumn{9}{|c|}{ Received any kind of HIV/STD-related knowledge in the last 12 months } \\
\hline Yes & $1.85(1.51 \sim 2.26) \dagger$ & $<0.001$ & $1.94(1.58 \sim 2.40) \dagger$ & $<0.001$ & $2.53(1.97 \sim 3.24) \dagger$ & $<0.001$ & $2.91(2.25 \sim 3.77) \dagger$ & $<0.001$ \\
\hline No & Ref. & & Ref. & & Ref. & & Ref. & \\
\hline \multicolumn{9}{|c|}{ Ever had HIV testing in the last 12 months } \\
\hline Yes & $2.32(1.30 \sim 4.15) \dagger$ & 0.005 & $2.11(1.20 \sim 3.69) \dagger$ & 0.009 & $3.06(1.39 \sim 6.74) \dagger$ & 0.006 & 3.09 (1.39 6.86)† & $<0.001$ \\
\hline No & Ref. & & Ref. & & Ref. & & Ref. & \\
\hline \multicolumn{9}{|c|}{ Ever had syphilis testing in the last 12 months } \\
\hline Yes & $0.70(0.50 \sim 0.98) \dagger$ & 0.048 & $0.75(0.53 \sim 1.06)$ & 0.101 & $1.73(1.11 \sim 2.69) \dagger$ & 0.016 & $1.87(1.19 \sim 2.94) \dagger$ & 0.007 \\
\hline No & Ref. & & Ref. & & Ref. & & Ref. & \\
\hline
\end{tabular}

*Adjusted model was adjusted for age (continuous), gender, ethnic, education, marital status and monthly income. $\dagger \mathrm{p}<0.05$.

STD, sexually transmitted diseases. 
Table 4 Factors associated with HIV and syphilis infection among heterosexual STD clinic patients, a cross-sectional survey in China 2016

\begin{tabular}{|c|c|c|c|c|c|c|c|c|}
\hline \multirow[b]{2}{*}{ Variables } & \multicolumn{4}{|c|}{ HIV infection* $(n=1177)$} & \multicolumn{4}{|c|}{ HIV infection* $(n=1177)$} \\
\hline & $\begin{array}{l}\text { Crude model } \\
\text { OR }(95 \% \mathrm{Cl})\end{array}$ & $\mathbf{P}$ & $\begin{array}{l}\text { Adjusted model } \\
\text { OR }(95 \% \mathrm{Cl})\end{array}$ & $\mathbf{P}$ & $\begin{array}{l}\text { Crude model } \\
\text { OR }(95 \% \mathrm{Cl})\end{array}$ & $\mathbf{P}$ & $\begin{array}{l}\text { Adjusted model } \\
\text { OR }(95 \% \mathrm{Cl})\end{array}$ & $\mathbf{P}$ \\
\hline \multicolumn{9}{|c|}{ Ever diagnosed with STD } \\
\hline Yes & $2.04(0.84 \sim 4.92)$ & 0.862 & $1.74(0.66 \sim 4.61)$ & 0.945 & $5.36(4.02 \sim 7.13) \dagger$ & $<0.001$ & $5.31(3.93 \sim 7.18) \dagger$ & $<0.001$ \\
\hline No & Ref. & & Ref. & & Ref. & & Ref. & \\
\hline \multicolumn{9}{|c|}{ Condom use in the last sexual encounter } \\
\hline No & $1.63(0.65 \sim 4.06)$ & 0.609 & $1.28(0.47 \sim 3.51)$ & 0.983 & $2.30(1.73 \sim 3.07) \dagger$ & $<0.001$ & $1.75(1.29 \sim 2.39) \dagger$ & $<0.001$ \\
\hline Yes & Ref. & & Ref. & & Ref. & & Ref. & \\
\hline \multicolumn{9}{|c|}{ Inconsistently used condom in the last 6 months } \\
\hline Yes & $1.01(0.29 \sim 3.49)$ & 0.993 & $0.89(0.24 \sim 3.39)$ & 0.875 & $1.59(1.10 \sim 2.30) \dagger$ & 0.014 & $1.04(0.71 \sim 1.54)$ & 0.827 \\
\hline No & Ref. & & Ref. & & Ref. & & Ref. & \\
\hline \multicolumn{9}{|c|}{ Ever had paid sex in the last 6 months } \\
\hline Yes & $3.47(1.57 \sim 7.67) \dagger$ & $<0.001$ & $2.00(1.24 \sim 3.12) \dagger$ & $<0.001$ & $0.99(0.70 \sim 1.41)$ & 0.782 & $1.12(0.76 \sim 1.64)$ & 0.748 \\
\hline No & Ref. & & Ref. & & Ref. & & Ref. & \\
\hline \multicolumn{9}{|c|}{ Condom use in the last paid sexual act } \\
\hline No & $2.02(0.49 \sim 8.25)$ & 0.329 & $1.16(0.20 \sim 6.83$ & 0.873 & $3.05(1.48 \sim 6.29) \dagger$ & 0.002 & $2.44(0.98 \sim 5.99)$ & 0.053 \\
\hline Yes & Ref. & & Ref. & & Ref. & & Ref. & \\
\hline \multicolumn{9}{|c|}{ Received any kind of HIV/STD-related knowledge in the last 12 months } \\
\hline Yes & $0.90(0.40 \sim 2.04)$ & 0.883 & $1.04(0.43 \sim 2.53)$ & 0.788 & $0.77(0.59 \sim 1.01)$ & 0.521 & $0.98(0.74 \sim 1.30)$ & 0.446 \\
\hline No & Ref. & & Ref. & & Ref. & & Ref. & \\
\hline
\end{tabular}

*Adjusted model was adjusted for age (continuous), gender, ethnic, education, marital status and monthly income. $\dagger p<0.05$.

STD, sexually transmitted diseases.

with the previous studies. ${ }^{12}{ }^{28-30}$ The potential reason is that participants who used condoms may have strong selfprotection awareness as well as a better understand of their potential risk of developing AIDS or other STDs and in turn have strong awareness of healthcare seeking. ${ }^{31}$ Although the effect of condom use on preventing the sexual transmission of HIV/syphilis has been clearly demonstrated, ${ }^{32}$ we found only around one-third of participants used condom in the last sexual intercourse and one-tenth used condom consistently, which highlights the importance of condom promotion among heterosexual STD clinic patients. Additionally, our study showed that participants who had ever paid sex were more likely to have both testing uptake. This may be partly attributable to higher risk perception of HIV/syphilis infection. ${ }^{33}$ Findings suggest that HIV and syphilis testing services that target heterosexual STD clinic attendees at high risk for HIV and syphilis infection may be strengthened by increasing the high perception of HIV/STD risk.

This study has several limitations. First, all the data were collected through self-report, which may be prone to information bias. Second, the participants were not randomly selected in this study. This may limit the external validity of our findings. Third, this study was cross-sectional, so relations should be interpreted as associations that might or might not be casual. Finally, this study could not account for many factors that likely influence the frequency of testing-policy environment, purpose of the patient's visit, clinic factors and local norms.

\section{CONCLUSIONS}

Our findings showed a low-level of HIV and syphilis testing uptake in STD clinic-based context in China, alongside with a high level of engagement in risky sexual behaviours, which indicates a high risk of HIV and syphilis infection among STD clinic patients. Future intervention programmes on promoting HIV and syphilis testing uptake among this population must be designed scientifically and take sexual behaviours, improvement of knowledge and awareness of HIV and syphilis infection into account.

\section{Author affiliations}

${ }^{1}$ STD Control Department, Dermatology Hospital, Southern Medical University, Guangzhou, China

${ }^{2}$ STD Control Department, Southern Medical University Institute for Global Health and Sexually Transmitted Diseases, Guangzhou, China

${ }^{3}$ STD Control Department, Guangdong Provincial Center for Skin Diseases and STIS Control, Guangzhou, China

${ }^{4}$ Project-China, University of North Carolina at Chapel Hill, Guangzhou, China ${ }^{5}$ Department of Ophthalmology, The Third Affiliated Hospital of Sun Yat-Sen University, Guangzhou, China

Correction notice This article has been corrected since it first published. The provenance and peer review statement has been included. 
Acknowledgements We thank all the study participants and staff members at Dongguan and Zhong Shan city who contributed.

Contributors $\mathrm{PZ}$ and $\mathrm{CW}$ participated in all stages and wrote the manuscript, $\mathrm{SH}$ helped collect the data; $\mathrm{HC}$ helped reviewed the English language. WT, HZ and BY helped design the study and reviewed the manuscript.

Funding Medical Scientific Research Foundation of Guangdong Province (A2018508, A2019524, A2019402, C2019122).

Disclaimer The funder had no role in study design or data collection, analysis or interpretation.

Competing interests None declared.

Patient and public involvement Patients and/or the public were not involved in the design, or conduct, or reporting, or dissemination plans of this research.

Patient consent for publication Not required.

Ethics approval The study was approved by the institutional review boards of the Dermatology Hospital of Southern Medical University (GDDHLS-20150309).

Provenance and peer review Not commissioned; externally peer reviewed.

Data availability statement Data are available upon reasonable request.

Open access This is an open access article distributed in accordance with the Creative Commons Attribution Non Commercial (CC BY-NC 4.0) license, which permits others to distribute, remix, adapt, build upon this work non-commercially, and license their derivative works on different terms, provided the original work is properly cited, appropriate credit is given, any changes made indicated, and the use is non-commercial. See: http://creativecommons.org/licenses/by-nc/4.0/.

\section{ORCID iDs}

Peizhen Zhao http://orcid.org/0000-0002-9334-3744

Weiming Tang http://orcid.org/0000-0002-9026-707X

Cheng Wang http://orcid.org/0000-0001-8000-9969

\section{REFERENCES}

1 UNAIDS. UNAIDS report on the global AIDS epidemic, 2010.

2 China CDC. Update on the AIDS/STD epidemic in China in December 2017,2018. Chin J AIDS STD;24:111.

3 Taylor MM, Kamb M, Wu D. Syphilis screening and treatment: integration with HIV services. Bull World Health Organ 2017;95:610.

4 Ahmed S, Schwarz M, Flick RJ, et al. Lost opportunities to identify and treat HIV-positive patients: results from a baseline assessment of provider-initiated HIV testing and counselling (PITC) in Malawi. Trop Med Int Health 2016;21:479-85.

5 Bassett IV, Walensky RP. Integrating HIV screening into routine health care in resource-limited settings. Clin Infect Dis 2010;50 Suppl 3:S77-84.

6 Hongcheng S, Shujie H MW, Fengying L. Effect analysis of promoting HIV and syphilis testing in Jiangmen, Guangdong. Chinese Journal of AIDS \& STD 2016;22:32-4.

7 Li Q, Xie P. Outpatient workload in China. Lancet 2013;381:1983-4.

8 Hongcheng S, Peizhen Z GS, Lei C. Promoting HIV and syphilis testing among sexually transmitted disease clinic attendees in the pearl River delta region, Guangdong. Modern Prev Med 2018;13:158-61.

9 Levi J, Raymond A, Pozniak A, et al. Can the UNAIDS 90-90-90 target be achieved? A systematic analysis of national HIV treatment cascades. BMJ Glob Health 2016;1:e10:e000010.

10 National Health Commission of the People's Republic of China. Chinese program for syphilis prevention and control(2010-2020), 2010
11 Ma Q, Pan X, Cai G, et al. The characteristics of heterosexual STD clinic attendees who practice oral sex in Zhejiang Province, China. PLoS One 2013;8:e67092.

12 Ma Q, Pan X, Cai G, et al. Hiv antibody testing and its correlates among heterosexual attendees of sexually transmitted disease clinics in China. BMC Public Health 2013;13:44.

13 Wang Q-Q, Chen X-S, Yin Y-P, et al. HIV/STD pattern and its associated risk factors among male STD clinic attendees in China: a foci for HIV intervention. BMC Public Health 2011;11:955.

14 Prevention CDC. Sexually transmitted disease surveillance, 2018.

15 National Health Commission of the People's Republic of China. Overview of the National statutory infectious diseases in 2018, 2019. Available: http://www.nhc.gov.cn/jkj/s3578/201904/050427ff3270 4a5db64f4ae1f6d57c6c.shtml

16 Wong NS, Huang S, Zheng $\mathrm{H}$, et al. Stages of syphilis in South China - a multilevel analysis of early diagnosis. BMC Public Health 2017;17.

17 Guangdong Bureau of Statistics. Guangdong Province yearly statistical data, 2020. Available: http://stats.gd.gov.cn/

18 World Health Organisation. Provider-initiated HIV testing and counselling in health facilities, 2007.

19 Chandisarewa W, Stranix-Chibanda L, Chirapa E, et al. Routine offer of antenatal HIV testing ("opt-out" approach) to prevent motherto-child transmission of HIV in urban Zimbabwe. Bull World Health Organ 2007;85:843-50.

20 Creek TL, Ntumy R, Seipone K, et al. Successful introduction of routine opt-out HIV testing in antenatal care in Botswana. $J$ Acquir Immune Defic Syndr 2007;45:102-7.

21 Mkwanazi NB, Patel D, Newell M-L, et al. Rapid testing may not improve uptake of HIV testing and same day results in a rural South African community: a cohort study of 12,000 women. PLoS One 2008;3:e3501.

22 Zou H, Zhang L, Chow EPF, et al. Testing for HIV/STIs in China: challenges, opportunities, and innovations. Biomed Res Int 2017;2017:1-3.

23 Wong NS, Tang W, Han L, et al. Msm HIV testing following an online testing intervention in China. BMC Infect Dis 2017;17:437.

24 Jiang Z, Xiu C, Yang J, et al. Hiv test uptake and related factors amongst heterosexual drug users in Shandong Province, China. PLoS One 2018;13:e204489.

25 Zhao J, Freeman B, Li M. Can mobile phone Apps influence people's health behavior change? an evidence review. J Med Internet Res 2016;18:e287.

26 Kharsany ABM, Karim QA, Karim SSA. Uptake of providerinitiated HIV testing and counseling among women attending an urban sexually transmitted disease clinic in South Africa - missed opportunities for early diagnosis of HIV infection. AIDS Care 2010;22:533-7

27 Nguyen VT, Nguyen HT, Nguyen QC, et al. Expenditure analysis of HIV testing and counseling services using the cascade framework in Vietnam. PLoS One 2015;10:e126659.

28 Ma Q, Pan X, Cai G, et al. The characteristics of heterosexual STD clinic attendees who practice oral sex in Zhejiang Province, China. PLoS One 2013;8:e67092.

29 Brinkley-Rubinstein L, Parker S, Gjelsvik A, et al. Condom use and incarceration among STI clinic attendees in the deep South. BMC Public Health 2016;16:971.

30 Hamlyn E, Welz T, Rebaudengo S, et al. Sexual behaviour, condom use and rates of sexually transmitted infections in HIV clinic attendees in South East London. Int J STD AIDS 2009;20:757-60.

31 Alkaiyat A, Schaetti C, Liswi M, et al. Condom use and HIV testing among men who have sex with men in Jordan. J Int AIDS Soc 2014;17:18573.

32 Xiao Z, Noar SM, Zeng L. Systematic review of HIV prevention interventions in China: a health communication perspective. Int $J$ Public Health 2014;59:123-42.

33 Han L, Zhou C, Li Z, et al. Differences in risk behaviours and HIV/STI prevalence between low-fee and medium-fee female sex workers in three provinces in China. Sex Transm Infect 2016;92:309-15. 